\title{
Selective coupling reaction between 2,6-diiodoanisoles and terminal alkynes catalyzed by palladium complex.
}

\section{Carlise Frota, Allan F. C. Rossini, Rogério A. Gariani and Cristiano Raminelli*}

Faculdade de Ciências Exatas e Tecnologia, Universidade Federal da Grande Dourados, Rodovia Dourados-Itahum, Km 12, Cidade Universitária, Dourados, MS, CEP 79.804-970, Brazil

*e-mail address: raminelli@ufgd.edu.br

Keywords: cross-coupling reaction, selective reaction, palladium catalysis

\section{INTRODUCTION}

The cross-coupling reaction between aryl halides and terminal alkynes catalyzed by palladium complexes and copper (I) salts can be considered an useful synthetic tool in the $\mathrm{C}\left(\mathrm{sp}^{2}\right)-\mathrm{C}(\mathrm{sp})$ bond formation leading to disubstituted acetylenic compounds. ${ }^{1}$ Accordingly, in this work we present our preliminary results involving the selective coupling reaction between 2,6-diiodoanisoles and terminal alkynes catalyzed by palladium and copper, in order to produce disubstituted alkynes bearing a functionalized aromatic ring.

\section{RESULTS AND DISCUSSION}

Initially, we treated 2,6-diiodoanisole (1a) with phenylacetylene (2a) employing a palladium salt or complex and Cul as catalysts under varied reaction conditions, in the attempt to obtain selectively the mono-coupling product $3 \mathbf{a}$ (Table 1).

Table 1. Synthesis of the compound $3 \mathbf{a}$.

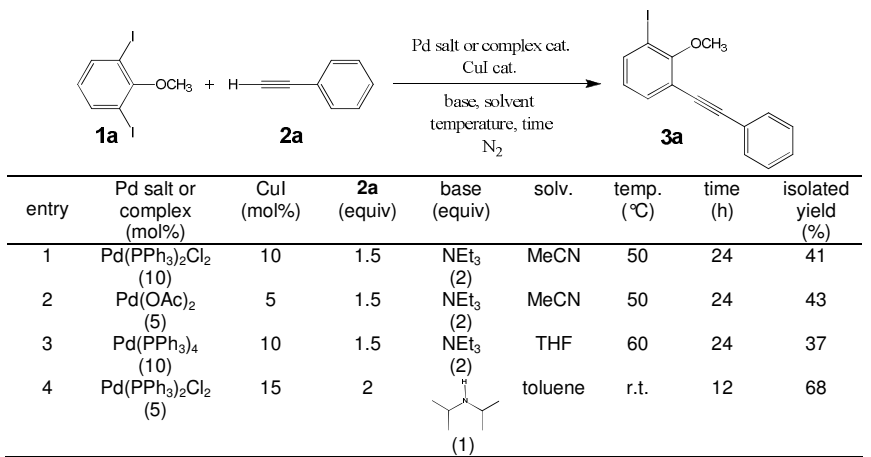

Aiming to obtain the mono-coupling product $\mathbf{3 a}$ in $\mathbf{a}$ better yield (Table 1, entry 4 ), subsequent work focused on optimization of the conditions for the reaction (Table 2 ).

Table 2. Optimization of the synthesis for the compound $\mathbf{3 a}$.

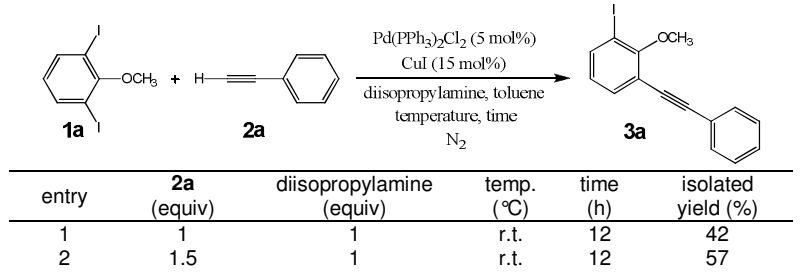

\begin{tabular}{llllll}
3 & 2 & 1 & & & \\
4 & 2 & 2 & r.t. & 12 & 68 \\
5 & 2 & 2 & 50 & 12 & 82 \\
6 & 2 & 2 & r.t. & 24 & 71 \\
\hline
\end{tabular}

Employing the optimized reaction conditions for the selective cross-coupling reaction between 2,6diiodoanisole (1a) and phenylacetylene (2a) (Table 2 , entry 4), we synthesized disubstituted alkynes bearing a functionalized aromatic ring (3) (Table 3).

Table 3. Synthesis of disubstituted alkynes bearing a functionalized aromatic ring (3). ${ }^{a}$

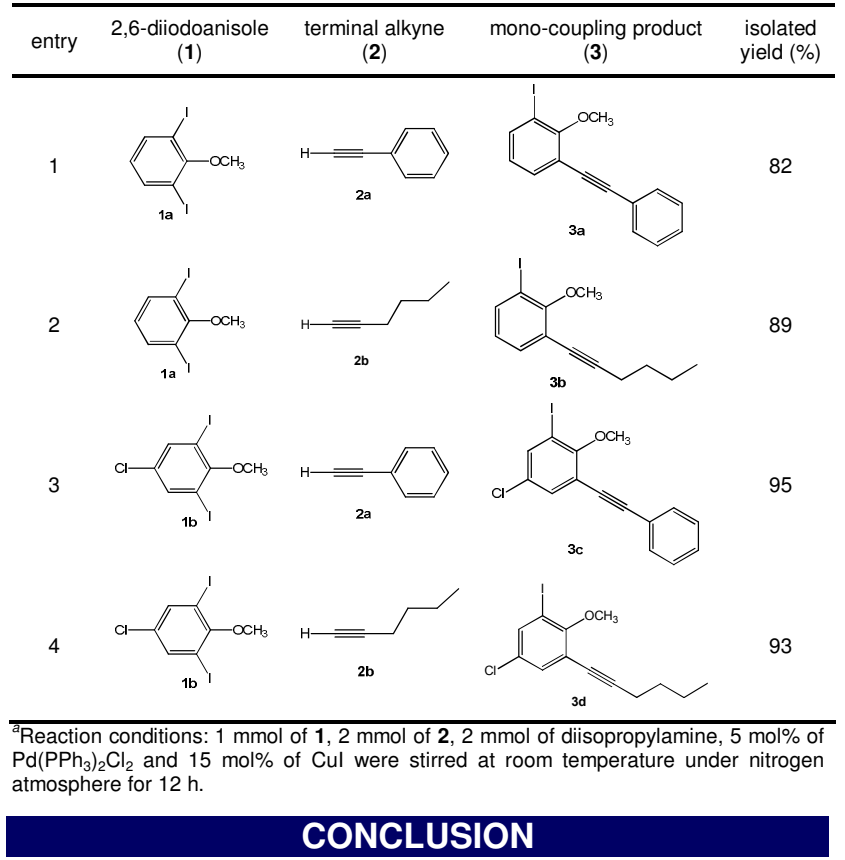

We optimized the reaction conditions for the selective coupling between 2,6-diiodoanisoles (1) and terminal alkynes (2) catalyzed by $\mathrm{Pd}\left(\mathrm{PPh}_{3}\right)_{2} \mathrm{Cl}_{2}$ and Cul, which produced disubstituted alkynes bearing a functionalized aromatic ring (3) in good yields.

\section{ACKNOWLEDGEMENTS}

We acknowledge CNPq and FUNDECT for financial support.

\section{REFERENCES}

${ }^{1}$ Chinchilla, R.; Nájera, C. Chem. Rev. 2007, 107, 874.

$14^{\text {th }}$ Brazilian Meeting on Organic Synthesis $-14^{\text {th }}$ BMOS - September 01-05, 2011-Brasilia, Brazil 